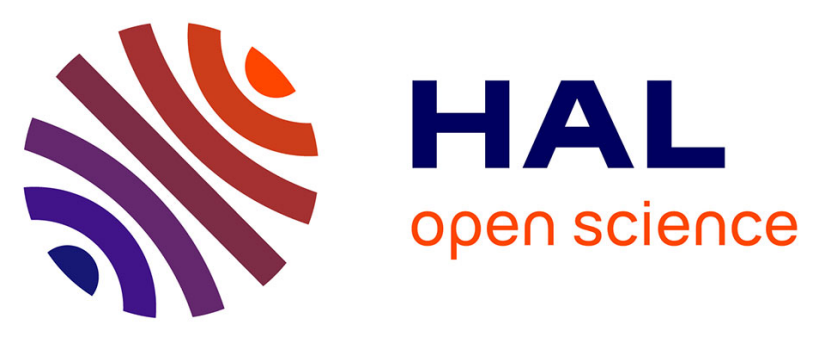

\title{
Wayanin and guaijaverin, two active metabolites found in a Psidium acutangulum Mart. ex DC (syn. P. persoonii McVaugh) (Myrtaceae) antimalarial decoction from the Wayana Amerindians
}

Emeline Houël, Flore Nardella, Valérie Jullian, Alexis Valentin, Catherine

Vonthron-Sénécheau, Pascal Villa, Adeline Obrecht, Marcel Kaiser, Eliane Bourreau, Guillaume Odonne, et al.

\section{- To cite this version:}

Emeline Houël, Flore Nardella, Valérie Jullian, Alexis Valentin, Catherine Vonthron-Sénécheau, et al.. Wayanin and guaijaverin, two active metabolites found in a Psidium acutangulum Mart. ex DC (syn. P. persoonii McVaugh) (Myrtaceae) antimalarial decoction from the Wayana Amerindians. Journal of Ethnopharmacology, 2016, 187, pp.241-248. 10.1016/j.jep.2016.04.053 hal-01313006

\section{HAL Id: hal-01313006 \\ https: / hal.sorbonne-universite.fr/hal-01313006}

Submitted on 9 May 2016

HAL is a multi-disciplinary open access archive for the deposit and dissemination of scientific research documents, whether they are published or not. The documents may come from teaching and research institutions in France or abroad, or from public or private research centers.
L'archive ouverte pluridisciplinaire $\mathbf{H A L}$, est destinée au dépôt et à la diffusion de documents scientifiques de niveau recherche, publiés ou non, émanant des établissements d'enseignement et de recherche français ou étrangers, des laboratoires publics ou privés. 


\section{ACCEPTED MANUSCRIPT}

Wayanin and guaijaverin, two active metabolites found in a Psidium acutangulum Mart. ex

DC (syn. P. persoonii McVaugh) (Myrtaceae) antimalarial decoction from the Wayana

Amerindians

Emeline Houël ${ }^{\mathrm{a}^{*}}$, Flore Nardella ${ }^{\mathrm{b}, \mathrm{c}}$, Valérie Jullian ${ }^{\mathrm{d}}$, Alexis Valentin ${ }^{\mathrm{d}}$, Catherine Vonthron-

Sénécheau ${ }^{\mathrm{b}}$, Pascal Villa ${ }^{\mathrm{e}}$, Adeline Obrecht $^{\mathrm{e}}$, Marcel Kaiser ${ }^{\mathrm{f}, \mathrm{g}}$, Eliane Bourreau ${ }^{\mathrm{h}}$, Guillaume

Odonne ${ }^{i}$, Marie Fleury ${ }^{j}$, Geneviève Bourdy $^{d}$, Véronique Eparvier ${ }^{k}$, Eric Deharo ${ }^{d}$, Didier

Stien $^{\mathrm{k}, 1^{*}}$

${ }^{a}$ CNRS, UMR EcoFoG (AgroParisTech, CIRAD, INRA, UA, UG), Institut Pasteur de la

Guyane, 23 Avenue Pasteur, BP6010, 97306 Cayenne Cedex, French Guiana

'Laboratoire d'Innovation Thérapeutique UMR CNRS 7200, LabEx Medalis, Faculté de

Pharmacie, Université de Strasbourg, 74 route du Rhin, 67401 Illkirch cedex, France

'Institut de Parasitologie et de Pathologie Tropicale de Strasbourg (IPPTS) - Faculté de

Médecine, Université de Strasbourg, Strasbourg, France

'UMR 152 Pharma Dev, Université de Toulouse, IRD, UPS, France

ePlate-forme de Chimie Biologique Intégrative de Strasbourg UMS 3286 CNRS-Université de Strasbourg, LabEx Medalis et FMTS, ESBS Pôle API, Bld Sébastien Brant, 67412 Illkirch Cedex, France

'Swiss Tropical and Public Health Institution, Socinstrasse 57, 4002 Basel, Switzerland

IUniversity of Basel, Petersplatz 1, 4003 Basel, Switzerland

hInstitut Pasteur de la Guyane, 23 Avenue Pasteur, BP6010, 97306 Cayenne Cedex, French Guiana

'Laboratoire Ecologie, évolution, interactions des systèmes amazoniens (LEEISA), CNRS, Université de Guyane, IFREMER, 97300 Cayenne, French Guiana 


\section{ACCEPTED MANUSCRIPT}

'Museum National d'Histoire Naturelle, UMR 208 PALoc, MNHN-IRD, BP 165, 97323

Cayenne cedex, French Guiana

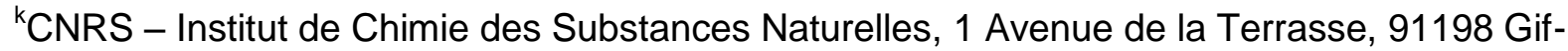
sur-Yvette Cedex, France

'Sorbonne Universités, UPMC Univ Paris 06, CNRS, Laboratoire de Biodiversité et Biotechnologies Microbiennes (LBBM), Observatoire Océanologique, 66650 Banyuls/Mer, France

*Corresponding authors. Tel.: +594 5942931 34; fax: +594 594309416. emeline.houel@ecofog.gf, Tel.: +33 4301924 76. didier.stien@cnrs.fr

Keywords: Psidium acutangulum; Traditional remedy; Cytokines; Antimalarial; Glycosylated flavonols; French Guiana

\section{Abstract}

\section{Ethnopharmacological relevance}

Psidium acutangulum Mart. ex DC is a small tree used by the Wayana Amerindians from the Upper-Maroni in French Guiana for the treatment of malaria.

\section{Aim of the study}

In a previous study, we highlighted the in vitro antiplasmodial, antioxidant and antiinflammatory potential of the traditional decoction of $P$. acutangulum aerial parts. Our goal was then to investigate on the origin of the biological activity of the traditional remedy, and eventually characterize active constituents.

Materials and methods 


\section{ACCEPTED MANUSCRIPT}

Liquid-liquid extractions were performed on the decoction, and the antiplasmodial activity evaluated against chloroquine-resistant FcB1 $\left(\left[{ }^{3} \mathrm{H}\right]-\right.$ hypoxanthine bioassay) and 7G8 (pLDH bioassay) $P$. falciparum strains, and on a chloroquine sensitive NF54 $\left(\left[{ }^{3} \mathrm{H}\right]\right.$-hypoxanthine bioassay) $P$. falciparum strain. The ethyl acetate fraction (D) was active and underwent bioguided fractionation. All the isolated compounds were tested on $P$. falciparum FcB1 strain. In vitro anti-inflammatory activity (IL-1 $\beta$, IL-6, IL-8, TNF $\alpha$ ) of the ethyl acetate fraction and of an anti-Plasmodium active compound, was concurrently assessed on LPS-stimulated human PBMC and NO secretion inhibition was measured on LPS stimulated RAW murine macrophages. Cytotoxicity of the fractions and pure compounds was measured on VERO cells, L6 mammalian cells, PBMCs, and RAW cells.

\section{Results}

Fractionation of the ethyl acetate soluble fraction $\left(\mathrm{IC}_{50}\right.$ ranging from 3.4 to $<1 \mu \mathrm{g} / \mathrm{mL}$ depending on the parasite strain) led to the isolation of six pure compounds: catechin and five glycosylated quercetin derivatives. These compounds have never been isolated from this plant species. Two of these compounds (wayanin and guaijaverin) were found to be moderately active against $P$. falciparum $\mathrm{FcB} 1$ in vitro $\left(\mathrm{IC}_{50} 5.5\right.$ and $6.9 \mu \mathrm{M}$ respectively). We proposed the name wayanin during public meetings organized in June 2015 in the UpperMaroni villages, in homage to the medicinal knowledge of the Wayana population. At 50 $\mu \mathrm{g} / \mathrm{mL}$, the ethyl acetate fraction (D) significantly inhibited IL-1 $\beta$ secretion (-46 \%) and NO production (-21\%), as previously observed for the decoction. The effects of $D$ and guiajaverin (4) on the secretion of other cytokines or NO production were not significant.

\section{Conclusions}

The confirmed antiplasmodial activity of the ethyl acetate soluble fraction of the decoction and of the isolated compounds support the previous results obtained on the $P$. acutangulum decoction. The antiplasmodial activity might be due to a mixture of moderately active non- 


\section{ACCEPTED MANUSCRIPT}

toxic flavonoids. The anti-inflammatory activities were less marked for ethyl acetate fraction

(D) than for the decoction.

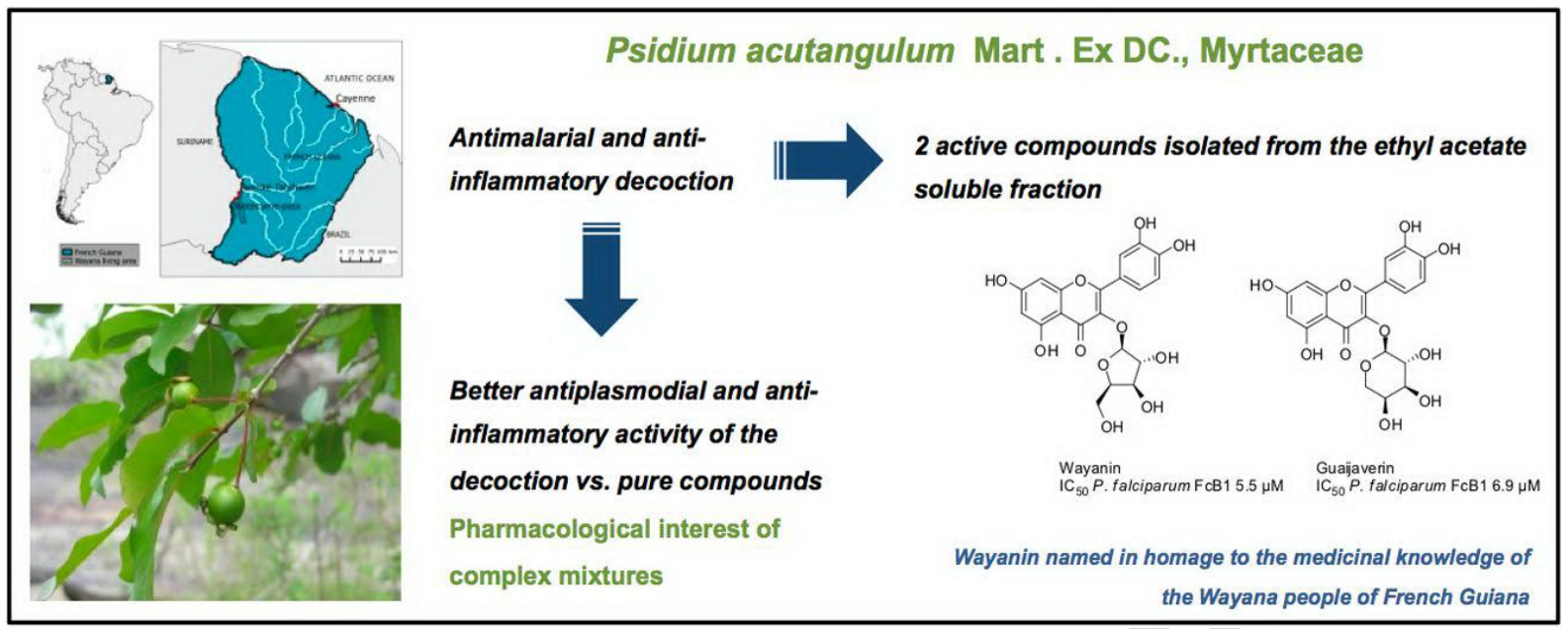

\section{Introduction}

Psidium acutangulum Mart. ex DC. is a shrub used by the local populations against diarrhea and abdominal pain (Fleury, 1991; Grenand et al., 2004). Its antimalarial use was reported during previous studies performed among the Upper-Maroni Wayana community (Fleury, 2003; 2007), where fresh aerial parts are prepared as a decoction. Patients with malaria crisis are washed with the remedy, and take it orally as well.

In Houël et al. (2015), we highlighted $P$. acutangulum decoction's antimalarial properties and demonstrated in vitro a significant dose dependent effect of the remedy on selected cytokines secretion and NO production, without cytotoxicity on L6 cell line, RAW cells and PBMC. This species is however poorly described on a phytochemical point of view, aside from the isolation of flavonols and $\alpha, \beta$-insaturated ketones (Miles et al., 1991; RiveroMaldonado et al., 2013), the latter family of compounds being interestingly known to exhibit antimalarial activity (Singh et al., 2014). Our aim was therefore to gain a better insight into the remedy's antimalarial and anti-inflammatory activities. 


\section{ACCEPTED MANUSCRIPT}

\section{Materials and methods}

\subsection{General experimental procedures}

${ }^{1} \mathrm{H}$ NMR spectra were recorded at $400 \mathrm{MHz}$ and ${ }^{13} \mathrm{C}$ NMR spectra at $100.6 \mathrm{MHz}$ on a Varian $400 \mathrm{MR}$ spectrometer equipped with a $5 \mathrm{~mm}$ inverse probe (Auto $X \mathrm{PGF}{ }^{1} \mathrm{H} /{ }^{15} \mathrm{~N}-{ }^{13} \mathrm{C}$ ). Samples were dissolved in deuterated acetone $\left(\mathrm{C}_{3} \mathrm{D}_{6} \mathrm{O}\right)$ or deuterated methanol $\left(C D_{3} \mathrm{OD}\right)$ in $5 \mathrm{~mm}$ tubes as stated. Chemical shifts are in ppm downfield from tetramethylsilane (TMS), and coupling constants $(\mathcal{J}$ ) are in $\mathrm{Hz}$ (s stands for singlet, $\mathrm{d}$ for doublet, t for triplet, $\mathrm{q}$ for quartet, $\mathrm{m}$ for multiplet, br for broad, ax for axial and eq for equatorial, and n.d. for not detected). ${ }^{13} \mathrm{C}$ chemical shifts were deduced from proton-carbon correlation experiments.

Water (HPLC grade) was obtained from a Milli-Q system (Milli-Q plus, Millipore Bedford, MA). Analyses were performed on a Discovery C18 column ( $15 \mathrm{~cm} \times 4.6 \mathrm{~mm}, 5 \mu \mathrm{m}$, Supelco) at 1 $\mathrm{mL} / \mathrm{min}$ using two HPLC systems (Waters and Varian). The first system was equipped with a W2996 photodiode array absorbance detector and a W2424 light-scattering detector (Waters) and the second system with a photodiode array absorbance detector (Varian). Preparative chromatography was performed at $15 \mathrm{~mL} / \mathrm{min}$ with a $\mathrm{W} 600$ pump and a $\mathrm{W} 2487$ double wavelength UV detector (Waters) using a Discovery C18 column (15 cm x $21.2 \mathrm{~mm}$, $5 \mu \mathrm{m}$, Supelco). Fractions were automatically collected (Waters Fraction Collector III) and evaporated à $37^{\circ} \mathrm{C}$ under reduced pressure with a speedvac concentrator (Savant SPD121P, Thermo Scientific).

UV spectra of pure compounds were measured with the W2996 photodiode array absorbance detector (Waters).

Radioactivity was counted using a Wallac® 1450 Betalux scintillation counter (1450Microbeta Trilux, Wallac Perkin Elmer). 


\section{ACCEPTED MANUSCRIPT}

2.2. Plant material

P. acutangulum stems, leaves, and fruits were collected in Twenke-Taluhwen (herbarium voucher MF2176, deposited in Cayenne Herbarium - CAY). Botanical identification was confirmed by Marie-Françoise Prévost. Aerial parts were dried prior to sample preparation to prevent degradation of the vegetal material during transportation between Twenke-Taluhwen and Cayenne.

\subsection{Ethical aspects of the study}

$P$. acutangulum was collected in Twenke-Taluhwen in February 2007 prior to the creation of the Amazonian Natural Park of French Guiana (PAG). Therefore, collect authorizations were unnecessary at the time of the collect. Interviews have been undertaken according to French Guiana legislation at the time of the study. The interviewees' participation to the study was voluntary, and as requested by the Wayana population, some of the results were published in a community-oriented booklet (Fleury, 2007). Moreover, public meetings were realized in June 2015 in the Upper-Maroni villages, where we proposed to give the name wayanin to quercetin-3-O- $\beta-D-x y l o f u r a n o s i d e$, with the agreement of the Wayana traditional authorities and in homage to the Wayana medicinal knowledge.

\subsection{Extraction and isolation}

$300 \mathrm{~mL}$ of a decoction (A) were prepared from $50 \mathrm{~g}$ of hand-crushed dried aerial parts of $P$. acutangulum (stems, leaves and fruits) placed in a 2-L Erlenmeyer flask with $1 \mathrm{~L}$ of cold water, and submitted to decoction during $2 \mathrm{~h}$. Leaves, stems, and fruits were removed by filtration after cooling and the decoction was submitted to successive liquid-liquid extractions. The decoction was first extracted with hexane $(3 \times 80 \mathrm{~mL})$. Filtration and evaporation of the solvent yielded $11.1 \mathrm{mg}$ of hexane extract $(\mathrm{B})$. The aqueous layer $(\mathrm{C})$ was then extracted with ethyl acetate $(3 \times 80 \mathrm{~mL})$. Filtration and evaporation of the solvent yielded $489.0 \mathrm{mg}$ of ethyl 


\section{ACCEPTED MANUSCRIPT}

acetate extract (D). Aliquots of the remaining aqueous phase $(E)$ were also evaporated and submitted to biological evaluation.

The antiplasmodial ethyl acetate extract (D) was diluted in water/acetonitrile (90:10). Separations were carried out on $1 \mathrm{~mL}$ of solution at $10 \mathrm{mg} / \mathrm{mL}$ using a linear gradient of water/acetonitrile (90:10 to 50:50 over $20 \mathrm{~min}$ ) and remaining at 100\% acetonitrile during 10 min to give 14 fractions. The eluates from the column were monitored at 214 and $254 \mathrm{~nm}$. Purification of $10 \mathrm{mg}$ of the crude extract allowed after evaporation for isolation of $0.9 \mathrm{mg}$ of compound 1, identified as catechin. For the other compounds, successive injections were performed and fractions containing the same compounds were put together, allowing after evaporation for isolation of $5.0 \mathrm{mg}$ of compound 2 from $55.0 \mathrm{mg}$ of crude extract, and for obtaining of $11.4 \mathrm{mg}$ of a mixture of compounds obtained from $70 \mathrm{mg}$ of crude extract. This mixture was then submitted to a second separation. This separation was carried out on using water/acetonitrile $83: 17$ for 20 min followed by a linear gradient from water/acetonitrile $83: 17$ to $50: 50$ over $5 \mathrm{~min}$. The eluates from the column were monitored at 214 and $254 \mathrm{~nm}$. Fractions containing the same constituents were gathered and evaporation allowed for isolation of compounds $3-6$ from $9.1 \mathrm{mg}$ of injected mixture. The isolated amounts of the pure compounds were the following: $3: 1.0 \mathrm{mg} ; 4: 0.4 \mathrm{mg} ; 5: 0.8 \mathrm{mg} ; 6: 0.4 \mathrm{mg}$. All compounds were isolated in pure form.

\subsection{Analytical data for compounds 1-6}

Catechin (1); UV $\lambda_{\max }\left(\mathrm{H}_{2} \mathrm{O} / \mathrm{ACN}\right) 279.6 \mathrm{~nm} ;{ }^{1} \mathrm{H} \mathrm{NMR}\left(400 \mathrm{MHz}, \mathrm{C}_{3} \mathrm{D}_{6} \mathrm{O}\right) \delta \mathrm{ppm} 6.89$ $\left(\mathrm{d}, J=2.0 \mathrm{~Hz}, 1 \mathrm{H}, \mathrm{H}_{2}{ }^{\prime}\right), 6.79\left(\mathrm{~d}, J=8.2 \mathrm{~Hz}, 1 \mathrm{H}, \mathrm{H}_{5}{ }^{\prime}\right), 6.75\left(\mathrm{dd}, J=8.2 ; 2.0 \mathrm{~Hz}, 1 \mathrm{H}, \mathrm{H}_{6}{ }^{\prime}\right), 6.02$ (d, $\left.J=2.3 \mathrm{~Hz}, 1 \mathrm{H}, \mathrm{H}_{6}\right), 5.88\left(\mathrm{~d}, J=2.3 \mathrm{~Hz}, 1 \mathrm{H}, \mathrm{H}_{8}\right), 4.56\left(\mathrm{~d}, J=7.8 \mathrm{~Hz}, 1 \mathrm{H}, \mathrm{H}_{2}\right), 3.99$ (br td, $J$ $\left.=8.2 ; 5.5 \mathrm{~Hz}, 1 \mathrm{H}, \mathrm{H}_{3}\right), 2.91\left(\mathrm{dd}, J=16.1 ; 5.5 \mathrm{~Hz}, 1 \mathrm{H}, \mathrm{H}_{4} \mathrm{a}\right), 2.53(\mathrm{dd}, J=16.1 ; 8.5 \mathrm{~Hz}, 1 \mathrm{H}$, $\mathrm{H}_{4}$ b). ${ }^{13} \mathrm{C}$ RMN (100.6 MHz, $\left.\mathrm{C}_{3} \mathrm{D}_{6} \mathrm{O}\right) \delta \mathrm{ppm} 158.2\left(\mathrm{C}_{7}\right), 157.7\left(\mathrm{C}_{5}\right), 156.9\left(\mathrm{C}_{9}\right), 146.39\left(\mathrm{C}_{3}\right)$, 


\section{ACCEPTED MANUSCRIPT}

$146.43\left(\mathrm{C}_{4^{\prime}}\right), 132.9\left(\mathrm{C}_{1^{\prime}}\right), 120.8\left(\mathrm{C}_{6^{\prime}}\right), 116.5\left(\mathrm{C}_{5^{\prime}}\right), 116.0\left(\mathrm{C}_{2^{\prime}}\right), 101.3\left(\mathrm{C}_{10}\right), 96.9\left(\mathrm{C}_{6}\right), 96.2\left(\mathrm{C}_{8}\right)$, $83.5\left(\mathrm{C}_{2}\right), 69.1\left(\mathrm{C}_{3}\right), 29.6\left(\mathrm{C}_{4}\right)$.

Quercetin-3-O- $\beta$-D-xylofuranoside (wayanin, 2); UV $\lambda_{\max }=265.3 / 352.3 \mathrm{~nm}$ $\left(\mathrm{H}_{2} \mathrm{O} / \mathrm{CH}_{3} \mathrm{CN}\right) ;{ }^{1} \mathrm{H}$ NMR $\left(400 \mathrm{MHz}, \mathrm{CD}_{3} \mathrm{OD}\right) \delta \mathrm{ppm} 7.56\left(\mathrm{~s}, 1 \mathrm{H}, \mathrm{H}_{2}\right) 7.54(\mathrm{~d}, J=8.4 \mathrm{~Hz}, 1 \mathrm{H}$, $\left.\mathrm{H}_{6^{\prime}}\right), 6.73\left(\mathrm{~m}, 1 \mathrm{H}, \mathrm{H}_{5^{\prime}}\right), 6.34\left(\mathrm{br} \mathrm{s}, 1 \mathrm{H}, \mathrm{H}_{6}\right), 6.18\left(\mathrm{br} \mathrm{s}, 1 \mathrm{H}, \mathrm{H}_{8}\right), 5.20\left(\mathrm{~d}, J=7.3 \mathrm{~Hz}, 1 \mathrm{H}, \mathrm{H}_{1^{\prime}}\right)$, 4.30 (m, 2H, $\mathrm{H}_{5}$ )), 3.49 (m, 3H, H2", H3", H4"). ${ }^{13} \mathrm{C}$ NMR (100.6 MHz, $\left.\mathrm{CD}_{3} \mathrm{OD}\right) \delta$ ppm n.d. $\left(\mathrm{C}_{4}\right), 165.8\left(\mathrm{C}_{7}\right), 162.6\left(\mathrm{C}_{5}\right), 159.1\left(\mathrm{C}_{2}\right), 158.0\left(\mathrm{C}_{9}\right), 149.4\left(\mathrm{C}_{4^{\prime}}\right), 145.5\left(\mathrm{C}_{3^{\prime}}\right), 135.0\left(\mathrm{C}_{3}\right), 123.3$ $\left(\mathrm{C}_{6^{\prime}}\right), 122.7\left(\mathrm{C}_{1^{\prime}}\right), 117.0\left(\mathrm{C}_{2^{\prime}}\right), 115.8\left(\mathrm{C}_{5^{\prime}}\right), 105.2\left(\mathrm{C}_{10}\right), 104.0\left(\mathrm{C}_{1^{\prime \prime}}\right), 99.7\left(\mathrm{C}_{8}\right), 94.5\left(\mathrm{C}_{6}\right), 77.9$ $\left(\mathrm{C}_{4^{\prime \prime}}\right), 75.6\left(\mathrm{C}_{2^{\prime \prime}}\right), 71.3\left(\mathrm{C}_{3^{\prime \prime}}\right), 64.1\left(\mathrm{C}_{5^{\prime \prime}}\right)$.

Quercetin-3-O- $\beta$-D-xylopyranoside (reynoutrin, 3); UV $\lambda_{\max }\left(\mathrm{H}_{2} \mathrm{O} / \mathrm{ACN}\right) 254.7 / 354.7$ $\mathrm{nm} ;{ }^{1} \mathrm{H}$ NMR $\left(400 \mathrm{MHz}, \mathrm{CD}_{3} \mathrm{OD}\right) \delta \mathrm{ppm} 7.60\left(\mathrm{dd}, J=2.1 ; 0.5 \mathrm{~Hz}, 1 \mathrm{H}, \mathrm{H}_{2^{\prime}}\right), 7.59$ (dd, $J=8.2$; $\left.2.1 \mathrm{~Hz}, 1 \mathrm{H}, \mathrm{H}_{6^{\prime}}\right), 6.85\left(\mathrm{dd}, J=8.2 ; 0.5 \mathrm{~Hz}, 1 \mathrm{H}, \mathrm{H}_{5^{\prime}}\right), 6.32\left(\mathrm{~d}, J=2.1 \mathrm{~Hz}, 1 \mathrm{H}, \mathrm{H}_{6}\right), 6.14(\mathrm{~d}, J=$ $\left.2.1 \mathrm{~Hz}, 1 \mathrm{H}, \mathrm{H}_{8}\right), 5.13\left(\mathrm{~d}, J=7.2 \mathrm{~Hz}, 1 \mathrm{H}, \mathrm{H}_{1^{\prime \prime}}\right), 3.78$ (dd, $\left.J=11.7 ; 5.1 \mathrm{~Hz}, 1 \mathrm{H}, \mathrm{H}_{5^{\prime \prime}} e q\right), 3.51$ (dd, $\left.J=8.8 ; 7.2 \mathrm{~Hz}, 1 \mathrm{H}, \mathrm{H}_{2^{\prime \prime}}\right), 3.51\left(\mathrm{~m}, 1 \mathrm{H}, \mathrm{H}_{4^{\prime \prime}}\right), 3.39\left(\mathrm{br} \mathrm{t}, J=8.6 \mathrm{~Hz}, 1 \mathrm{H}, \mathrm{H}_{3^{\prime \prime}}\right), 3.10(\mathrm{dd}, J=11.7$; $\left.9.5 \mathrm{~Hz}, 1 \mathrm{H}, \mathrm{H}_{5^{\prime \prime}} \mathrm{ax}\right) .{ }^{13} \mathrm{C} \mathrm{NMR}\left(100.6 \mathrm{MHz}, \mathrm{CD}_{3} \mathrm{OD}\right) \delta \mathrm{ppm} 178.4\left(\mathrm{C}_{4}\right), 166.8\left(\mathrm{C}_{7}\right), 162.5\left(\mathrm{C}_{5}\right)$, $158.4\left(\mathrm{C}_{9}\right), 158.0\left(\mathrm{C}_{2}\right), 149.6\left(\mathrm{C}_{4^{\prime}}\right), 145.7\left(\mathrm{C}_{3^{\prime}}\right), 134.9\left(\mathrm{C}_{3}\right), 123.0\left(\mathrm{C}_{6^{\prime}}\right), 122.6\left(\mathrm{C}_{1^{\prime}}\right), 116.8\left(\mathrm{C}_{2^{\prime}}\right)$, $115.7\left(\mathrm{C}_{5^{\prime}}\right), 104.6\left(\mathrm{C}_{1^{\prime \prime}}\right), 104.1\left(\mathrm{C}_{10}\right), 100.7\left(\mathrm{C}_{8}\right), 95.2\left(\mathrm{C}_{6}\right), 77.4\left(\mathrm{C}_{3^{\prime \prime}}\right), 75.0\left(\mathrm{C}_{2^{\prime \prime}}\right), 70.8\left(\mathrm{C}_{4^{\prime \prime}}\right)$, $66.9\left(\mathrm{C}_{5}\right)$

Quercetin-3-O- $\alpha$-L-arabinopyranoside (guaijaverin, 4); UV $\lambda_{\max }\left(\mathrm{H}_{2} \mathrm{O} / \mathrm{ACN}\right) 254.7$ / $358.8 \mathrm{~nm} ;{ }^{1} \mathrm{H}$ NMR (400 MHz, $\left.\mathrm{CD}_{3} \mathrm{OD}\right) \delta \mathrm{ppm} 7.74\left(\mathrm{~d}, J=2.2 \mathrm{~Hz}, 1 \mathrm{H}, \mathrm{H}_{2^{\prime}}\right), 7.58(\mathrm{dd}, J=8.5$; $\left.2.2 \mathrm{~Hz}, 1 \mathrm{H}, \mathrm{H}_{6^{\prime}}\right), 6.86\left(\mathrm{~d}, J=8.5 \mathrm{~Hz}, 1 \mathrm{H}, \mathrm{H}_{5^{\prime}}\right), 6.33\left(\mathrm{~d}, J=2.0 \mathrm{~Hz}, 1 \mathrm{H}, \mathrm{H}_{6}\right), 6.15(\mathrm{~d}, J=2.0 \mathrm{~Hz}$, $\left.1 \mathrm{H}, \mathrm{H}_{8}\right), 5.11\left(\mathrm{~d}, J=6.6 \mathrm{~Hz}, 1 \mathrm{H}, \mathrm{H}_{1^{\prime \prime}}\right), 3.90\left(\mathrm{dd}, J=8.4 ; 6.6 \mathrm{~Hz}, 1 \mathrm{H}, \mathrm{H}_{2^{\prime \prime}}\right), 3.82(\mathrm{dd}, J=12.4$; $2.9 \mathrm{~Hz}, 1 \mathrm{H}, \mathrm{H}_{5^{\prime \prime}}$ ), $3.81\left(\mathrm{~m}, 1 \mathrm{H}, \mathrm{H}_{4}{ }^{\prime \prime}\right), 3.64\left(\mathrm{dd}, J=8.4\right.$; $\left.3.2 \mathrm{~Hz}, 1 \mathrm{H}, \mathrm{H}_{3^{\prime \prime}}\right), 3.44(\mathrm{dd}, J=12.4$; 3.0 Hz, 1H, $\left.\mathrm{H}_{5}{ }^{\prime} \mathrm{a}\right) .{ }^{13} \mathrm{C} \mathrm{NMR}\left(100.6 \mathrm{MHz}, \mathrm{CD}_{3} \mathrm{OD}\right) \delta \mathrm{ppm} 178.0\left(\mathrm{C}_{4}\right), 168.0\left(\mathrm{C}_{7}\right), 160.5\left(\mathrm{C}_{5}\right)$, $158.6\left(\mathrm{C}_{9}\right), 157.8\left(\mathrm{C}_{2}\right), 149.9\left(\mathrm{C}_{4^{\prime}}\right), 145.8\left(\mathrm{C}_{3^{\prime}}\right), 135.1\left(\mathrm{C}_{3}\right), 122.6\left(\mathrm{C}_{6^{\prime}}\right), 122.5\left(\mathrm{C}_{1^{\prime}}\right), 117.0\left(\mathrm{C}_{2^{\prime}}\right)$, $115.9\left(\mathrm{C}_{5^{\prime}}\right), 104.7\left(\mathrm{C}_{1^{\prime \prime}}\right), 104.3\left(\mathrm{C}_{10}\right), 100.9\left(\mathrm{C}_{8}\right), 95.4\left(\mathrm{C}_{6}\right), 74.0\left(\mathrm{C}_{3^{\prime \prime}}\right), 72.7\left(\mathrm{C}_{2^{\prime \prime}}\right), 68.9\left(\mathrm{C}_{4^{\prime \prime}}\right)$, $66.8\left(\mathrm{C}_{5^{\prime \prime}}\right)$ 


\section{ACCEPTED MANUSCRIPT}

Quercetin-3-O- $\alpha$-L-arabinofuranoside (avicularin, 5); UV $\lambda_{\max }\left(\mathrm{H}_{2} \mathrm{O} / \mathrm{ACN}\right) 255.9$ / 351.1

nm. ${ }^{1} \mathrm{H}$ NMR (400 MHz, CD $\left.{ }_{3} \mathrm{OD}\right) \delta$ ppm $7.52\left(\mathrm{~d}, J=2.0 \mathrm{~Hz}, 1 \mathrm{H}, \mathrm{H}_{2}\right), 7.48(\mathrm{dd}, J=8.4 ; 2.0$ $\left.\mathrm{Hz}, 1 \mathrm{H}, \mathrm{H}_{6^{\prime}}\right), 6.89\left(\mathrm{~d}, J=8.4 \mathrm{~Hz}, 1 \mathrm{H}, \mathrm{H}_{5^{\prime}}\right), 6.34\left(\mathrm{~d}, J=2.1 \mathrm{~Hz}, 1 \mathrm{H}, \mathrm{H}_{6}\right), 6.17(\mathrm{~d}, J=2.1 \mathrm{~Hz}$, $1 \mathrm{H}, \mathrm{H}_{8}$ ), 5.45 (brs, $1 \mathrm{H}, \mathrm{H}_{1 "}$ ), 4.32 (dd, $\left.J=2.9,1.0 \mathrm{~Hz}, 1 \mathrm{H}, \mathrm{H}_{2^{\prime \prime}}\right), 3.91$ (dd, $J=5.2 ; 2.9 \mathrm{~Hz}, 1 \mathrm{H}$, $\mathrm{H}_{3^{\prime \prime}}$ ), 3.87 (brq, $\left.J=4.5 \mathrm{~Hz}, 1 \mathrm{H}, \mathrm{H}_{4 "}\right), 3.49\left(\mathrm{~m}, 1 \mathrm{H}, \mathrm{H}_{5^{\prime \prime}}\right.$ ), 3.48 (dd, $J=12.0 ; 4.6 \mathrm{~Hz}, 1 \mathrm{H}, \mathrm{H}_{5^{\prime \prime}}$ ). ${ }^{13} \mathrm{C}$ NMR $\left(100.6 \mathrm{MHz}, \mathrm{CD}_{3} \mathrm{OD}\right) \delta \mathrm{ppm} 176.5\left(\mathrm{C}_{4}\right), 167.9\left(\mathrm{C}_{7}\right), 163.0\left(\mathrm{C}_{5}\right), 158.9\left(\mathrm{C}_{2}\right), 158.7$ $\left(\mathrm{C}_{9}\right), 149.7\left(\mathrm{C}_{4^{\prime}}\right), 146.2\left(\mathrm{C}_{3^{\prime}}\right), 134.6\left(\mathrm{C}_{3}\right), 122.8\left(\mathrm{C}_{1^{\prime}}\right), 122.6\left(\mathrm{C}_{6^{\prime}}\right), 116.5\left(\mathrm{C}_{2^{\prime}}\right), 116.1\left(\mathrm{C}_{5^{\prime}}\right), 109.3$ $\left(\mathrm{C}_{1^{\prime \prime}}\right), 104.6\left(\mathrm{C}_{10}\right), 99.7\left(\mathrm{C}_{8}\right), 94.5\left(\mathrm{C}_{6}\right), 87.7\left(\mathrm{C}_{4^{\prime \prime}}\right), 83.0\left(\mathrm{C}_{2^{\prime \prime}}\right), 78.4\left(\mathrm{C}_{3^{\prime \prime}}\right), 62.2\left(\mathrm{C}_{5^{\prime \prime}}\right)$.

Quercetin-3-O- $\alpha$-L-rhamnopyranoside (quercitrin, 6); UV $\lambda_{\max }\left(\mathrm{H}_{2} \mathrm{O} / \mathrm{ACN}\right) 254.7$ / $345.1 \mathrm{~nm} .{ }^{1} \mathrm{H}$ NMR $\left(400 \mathrm{MHz}, \mathrm{CD}_{3} \mathrm{OD}\right) \delta \mathrm{ppm} 7.33\left(\mathrm{~d}, J=2.1 \mathrm{~Hz}, 1 \mathrm{H}, \mathrm{H}_{2}\right), 7.30(\mathrm{dd}, J=8.2$; $\left.2.1 \mathrm{~Hz}, 1 \mathrm{H}, \mathrm{H}_{6^{\prime}}\right), 6.90\left(\mathrm{~d}, J=8.2 \mathrm{~Hz}, 1 \mathrm{H}, \mathrm{H}_{5^{\prime}}\right), 6.31\left(\mathrm{~d}, J=2.1 \mathrm{~Hz}, 1 \mathrm{H}, \mathrm{H}_{6}\right), 6.15(\mathrm{~d}, J=2.1 \mathrm{~Hz}$, $\left.1 \mathrm{H}, \mathrm{H}_{8}\right), 5.34\left(\mathrm{~d}, J=1.7 \mathrm{~Hz}, 1 \mathrm{H}, \mathrm{H}_{1^{\prime \prime}}\right), 4.21\left(\mathrm{dd}, J=3.4 ; 1.7 \mathrm{~Hz}, 1 \mathrm{H}, \mathrm{H}_{2^{\prime \prime}}\right), 3.74(\mathrm{dd}, J=9.4$; $\left.3.4 \mathrm{~Hz}, 1 \mathrm{H}, \mathrm{H}_{3^{\prime \prime}}\right), 3.42\left(\mathrm{~m}, 1 \mathrm{H}, \mathrm{H}_{5^{\prime \prime}}\right), 3.34\left(\mathrm{~m}, 1 \mathrm{H}, \mathrm{H}_{4^{\prime \prime}}\right), 0.94\left(\mathrm{~d}, \mathrm{~J}=6.1 \mathrm{~Hz}, 3 \mathrm{H}, \mathrm{H}_{6^{\prime \prime}}\right) .{ }^{13} \mathrm{C} N M R$ (100.6 MHz, $\left.\mathrm{CD}_{3} \mathrm{OD}\right)$ ס ppm $179.3\left(\mathrm{C}_{4}\right), 168.6\left(\mathrm{C}_{7}\right), 162.7\left(\mathrm{C}_{5}\right), 158.6\left(\mathrm{C}_{2}\right), 159.9\left(\mathrm{C}_{9}\right), 149.4$ $\left(\mathrm{C}_{4^{\prime}}\right), 149.6\left(\mathrm{C}_{3^{\prime}}\right), 133.7\left(\mathrm{C}_{3}\right), 122.8\left(\mathrm{C}_{1^{\prime}}\right), 122.5\left(\mathrm{C}_{6^{\prime}}\right), 116.6\left(\mathrm{C}_{2^{\prime}}\right), 116.1\left(\mathrm{C}_{5^{\prime}}\right), 106.2\left(\mathrm{C}_{10}\right)$, $103.4\left(\mathrm{C}_{1^{\prime \prime}}\right), 100.5\left(\mathrm{C}_{8}\right), 95.1\left(\mathrm{C}_{6}\right), 72.7\left(\mathrm{C}_{4^{\prime \prime}}\right), 71.8\left(\mathrm{C}_{2^{\prime \prime}}\right), 71.8\left(\mathrm{C}_{3^{\prime \prime}}\right), 17.4\left(\mathrm{C}_{6^{\prime \prime}}\right)$.

Spectra obtained from proton and proton-carbon correlation experiments are given as Supplementary Data.

\subsection{In vitro antiplasmodial activity}

\subsection{1. $\left[{ }^{3} \mathrm{H}\right]$-hypoxanthine assay}

$\left[{ }^{3} \mathrm{H}\right]$-hypoxanthine assays were performed on P. falciparum FcB1 strain (chloroquine resistant) and NF54 strain (chloroquine sensitive) according to a procedure adapted from Le Bras and Deloron (1983) and Benoit et al. (1996) as reported previously (Houël et al., 2015). Decreasing concentrations of the extracts and pure compounds (100 to $1 \mu \mathrm{g} / \mathrm{mL}, 3$ concentrations for FcB1 strain and 100 to $0.002 \mu \mathrm{g} / \mathrm{mL}, 11$ concentrations for NF54 strain) 


\section{ACCEPTED MANUSCRIPT}

were used. Each experiment was performed 3 times in triplicate, and negative (DMSO) and positive (chloroquine) controls were also performed. Growth/inhibition percentage curves were obtained and the concentration required to inhibit $50 \%$ growth $\left(\mathrm{IC}_{50}\right)$ was determined graphically (FcB1 strain) or calculated by linear regression (NF54 strain). $\left[{ }^{3} \mathrm{H}\right]-$ hypoxanthine was discarded according to French legislation on elimination of radioactive residue (www.asn.fr/).

\subsection{2. pLDH assay}

pLDH immunodetection assays were performed against $P$. falciparum 7G8 chloroquineresistant strain, with a commercially available sandwich enzyme immunosorbent assay (ApDia), as reported previously (Atchade et al., 2013). Parasite culture (1\% parasitaemia, 2\% hematocrit) was incubated with increasing concentrations of the extract ( 1 to $100 \mu \mathrm{g} / \mathrm{ml}, 8$ concentrations) for $96 \mathrm{~h}$ at $7^{\circ} \mathrm{C}$ under reduced oxygen conditions (candle jar). Each experiment was performed 3 times in duplicate, and chloroquine was used as a positive control. IC $\mathrm{I}_{50}$ were calculated with GraphPad Prism 6 software.

\subsection{In vitro anti-inflammatory activity}

\subsubsection{Inhibitory activity on NO production from macrophage-like cell line RAW 264.7}

The bioassays were performed as reported previously (Houël et al., 2015). Briefly, RAW 264.7 cells (ATCC TIB-71) were stimulated with lipopolysaccharide (LPS, Sigma, $5 \mu \mathrm{g} / \mathrm{mL}$ ) and treated with 2 concentrations of ethyl acetate fraction (D) or pure guaijaverin (4) (50 $\mu \mathrm{g} / \mathrm{mL}$ or $10 \mu \mathrm{g} / \mathrm{mL}$,) diluted in DMSO. Quercetin at $50 \mu \mathrm{g} / \mathrm{mL}$ and $10 \mu \mathrm{g} / \mathrm{mL}$ (final DMSO concentration $1 \% \mathrm{v} / \mathrm{v}$ ) was used as a positive control. Unstimulated cells (without LPS) are considered as negative control. Plates were then incubated for $24 \mathrm{~h}$ and nitrite $\left(\mathrm{NO}_{2}{ }^{-}\right)$ accumulation was determined as an indicator of NO production in culture media as previously described (Kumar-Roiné et al., 2009). Each measurement was performed in triplicate and results were expressed as means for three independent experiments. 
Cytotoxicity was measured by the WST-1 assay (Ozyme, according to supplier protocol). All experiments were performed on a fully automated platform (Beckman Coulter).

\subsubsection{Peripheral blood mononuclear cells (PBMCs) isolation and culture}

PBMCs were prepared from the peripheral blood of healthy donors (Etablissement Français du Sang) as reported previously (Houël et al., 2015). Isolated PBMCs were stimulated with 5 $\mu \mathrm{g} / \mathrm{mL}$ LPS (Sigma). Ethyl acetate fraction (D) or pure guaijaverin (4) were dissolved in DMSO so that final DMSO concentration is $1 \%$ and tested at 10 and $50 \mu \mathrm{g} / \mathrm{mL}$ in triplicate. Positive control dexamethasone dissolved in ethanol so that final EtOH concentration is $1 \%$ was simultaneously tested at 10 and $50 \mu \mathrm{g} / \mathrm{mL}$. Cells without LPS stimulation were considered as negative control (basal level of cytokine). Cells incubation was carried out at $37^{\circ} \mathrm{C}\left(5 \% \mathrm{CO}_{2}\right)$.

\subsubsection{Characterization of cytokine secretion.}

After 24 h, PBMCs supernatants were transferred into a 384-well plate. Cytokine detection was performed using HTRF technology (Homogeneous Time Resolved Fluorescence, Cisbio bioassays) for TNFa (62TNFPEC), IL-1ß (62IL1PEC), IL-6 (62IL6PEB), IL-8 (62IL8PEB) according to supplier recommendations. Reading was performed after $2.5 \mathrm{~h}$ of incubation using Envision multi-labelled reader (Perkin Elmer) with supplier recommended parameters. A standard curve was performed for each cytokine to determine the concentration of released cytokines (in $\mathrm{pg} / \mathrm{mL}$ ) by PBMCs in the supernatant. The cytokine secretion is expressed as a percentage of the cytokine concentration measured in the negative control experiment conducted on the same plate.

\subsubsection{Cell viability assay}

Cell viability was measured using the WST-1 (Ozyme) assay according to the manufacturers' protocol. Briefly, after supernatant transfer for cytokine determination, WST-1-containing medium was added to cells and cell viability was determined by measuring absorbance at 
$450 \mathrm{~nm}$ using Victor $^{3}$ reader (Perkin Elmer) after $2 \mathrm{~h}$ incubation at $37^{\circ} \mathrm{C}$. Each measurement was performed in triplicate and results were expressed as means of three independent experiments.

\subsection{In vitro cytotoxicity study}

\subsubsection{In vitro cytotoxicity study on VERO cells}

Cytotoxicity on VERO cells (African Green Monkey kidney epithelial cells) was evaluated as reported previously (Cachet et al., 2009). Briefly, the cell line was cultured under the same conditions as used for $P$. falciparum, except for the $5 \%$ human serum, which was replaced by $10 \%$ fetal calf serum (Boehringer). Cells were seeded $\left(2 \times 10^{5}\right.$ cells/well) during their log growth phase in 96-well flat-bottom plates after addition of trypsin. Cells were cultured for 72 $\mathrm{h}$ at $37^{\circ} \mathrm{C}$ and $5 \% \mathrm{CO}_{2}$, extracts/molecules being added after $24 \mathrm{~h}$, at concentrations ranging from $100 \mu \mathrm{g} / \mathrm{ml}$ to $0.01 \mu \mathrm{g} / \mathrm{ml}$. Cell growth was measured by $\left[{ }^{3} \mathrm{H}\right]$-hypoxanthine incorporation after a $48 \mathrm{~h}$ incubation. The amount of $\left[{ }^{3} \mathrm{H}\right]$-hypoxanthine incorporated in the presence of drugs was compared with that of control cultures (solvent for negative control, doxorubicin for positive control). All experiments were performed in triplicate.

\subsubsection{In vitro cytotoxicity study on L-6 cells}

The cytotoxicity of the fractions was assessed by using the L-6 cell line (rat skeletal myoblasts) and the method of Ahmed et al. (1994). The cytotoxicity assays were performed according to previously published procedures (Houël et al., 2015). After incubation $\left(37^{\circ} \mathrm{C}, 5 \%\right.$ $\mathrm{CO}_{2}$ ) with the drugs for 70 hours and further 2 hours with resazurin, the plates were read with a Spectramax Gemini XS microplate fluorometer at an excitation wavelength of $536 \mathrm{~nm}$ and an emission wavelength of $588 \mathrm{~nm}$. The $\mathrm{IC}_{50}$ values were calculated from the sigmoidal inhibition curves with SoftMax Pro software. Podophyllotoxin (Sigma) was used as a positive control. The given values are the means of two independent assays. 


\section{ACCEPTED MANUSCRIPT}

2.9. Statistical analysis

Data were analysed by one-way analysis of variance followed by Tukey's multiple comparison tests using GraphPad Software version 5.04. $P<0.05$ was considered significant. In figures 2 and 3, whiskers show the maximal and minimal values. The rectangular box represents the $25 \%$ quantile to $75 \%$ quantile ranges. The dark line shows the median of the distribution.

\section{Results and discussion}

3.1. Characterization of compounds from the ethyl acetate fraction (D) of the decoction Antiplasmodial activity of the decoction and of liquid phases obtained during successive extractions was evaluated, and it was found that the ethyl acetate extract (D) was the most active. Naturally, this extract was chosen for bioguided fractionation. The following metabolites were isolated and identified by 1D and 2D NMR spectroscopy, and by comparison with published data: catechin (1, 9.1\% w/w) (Davis et al., 1996), wayanin (quercetin-3-O- $\beta$-D-xylofuranoside, 2, $9.1 \%$ w/w) (Moravcova et al., 1997; Saldanha et al., 2013; Saxena et Chaturvedi, 1992; Vvedenskaya et al., 2004; Xue et al., 2006), reynoutrin (quercetin-3-O- $\beta$-D-xylopyranoside, 3, $1.8 \%$ w/w) (Eparvier et al., 2007; Lu and Yeap Foo, 1997), guaijaverin (quercetin-3-O- $\alpha$-L-arabinopyranoside, 4, $0.7 \%$ w/w) (Stark et al., 2005; Vvedenskaya et al., 2004), avicularin (quercetin-3-O- $\beta$-L-arabinofuranoside, 5, $1.5 \% \mathrm{w} / \mathrm{w}$ ) (Lu and Yeap Foo, 1997; Vvedenskaya et al., 2004) and quercitrin (quercetin-3-O-a-Lrhamnopyranoside, 6, 0.7 \% w/w) (Lu and Yeap Foo, 1997) (Fig. 1). Isolation yields are given in \% based on dry ethyl acetate crude extract. Quercetin-3-O- $\beta$-D-xylofuranoside, which we named wayanin, was recently isolated from Myrcia bella Cambess. (Myrtaceae) leaves hydroalcoolic extract concurrently with avicularin, quercitrin and reynoutrin (Saldanha et al., 2013). Reynoutrin has been isolated recently from the genus Psidium (Ho et al., 2012). Avicularin and guaijaverin are known since the late 1950s as constituents of $P$. guajava 


\section{ACCEPTED MANUSCRIPT}

leaves (El Khadem and Mohammed, 1958). These widely ubiquitous compounds frequently coexist, together with catechin and quercitrin, particularly within the Myrtaceae family (Gallo et al., 2008; Shu et al., 2012; Simirgiotis et al., 2008). These molecules are described for the first time in Psidium acutangulum. In fact, only few compounds had been previously described in $P$. acutangulum, among which the $\alpha, \beta$-insaturated ketone 3'-formyl-2',4',6'trihydroxy-5'-methyldihydrochalcone, isolated from a dichloromethane extract (Miles et al., 1991), and myricetin, identified in P. acutangulum leaves (Rivero-Maldonado et al.,2013).<smiles>Oc1cc(O)c2c(c1)O[C@H](c1ccc(O)c(O)c1)C(O)C2</smiles>

(1) catechin

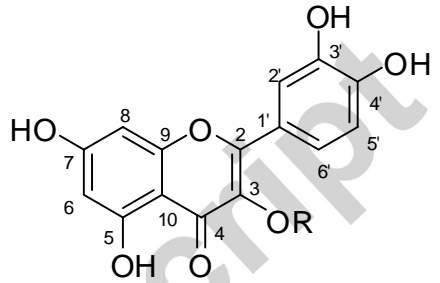

(2) $R=\beta-D$-xylofuranose (wayanin)

(3) $R=\beta$-D-xylopyranose (reynoutrin)

(4) $R=\alpha$-L-arabinopyranose (guaijaverin)

(5) $R=\alpha-L$-arabinof uranose (avicularin)

(6) $R=\alpha$-L-rhamnopyranose (quercitrin)<smiles>OC[C@H]1O[C@@H](O)[C@@H](O)[C@@H]1O</smiles>

$\beta$-D-xylofuranose

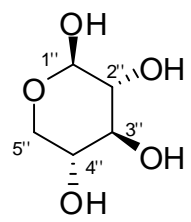

$\beta$-D-xylopyranose<smiles>OC[C@H]1OC(O)[C@@H](O)[C@H]1O</smiles><smiles>C[C@@H]1OC(O)[C@H](O)[C@H](O)C1O</smiles>

Fig. 1. Catechin and glycosylated quercetin derivatives isolated from $P$. acutangulum decoction

\subsection{Biological activities}

The decoction $(\mathrm{A})$ had been shown to display a good antiplasmodial activity in vitro against various strains, regardless to the bioassay used, with $\mathrm{IC}_{50}$ values of $3.3 \mu \mathrm{g} / \mathrm{mL}$ and 10.3 $\mu \mathrm{g} / \mathrm{mL}$ against $P$. falciparum FcB1 and NF54, respectively and $19.0 \mu \mathrm{g} / \mathrm{mL}$ against $P$. falciparum 7G8 (Houël et al., 2015), and these results are reminded about in Table 1. The 


\section{ACCEPTED MANUSCRIPT}

successive extracts $(B-E)$ obtained through liquid-liquid fractionation were therefore

submitted to antimalarial tests in vitro, using $P$. falciparum chloroquine-resistant FcB1 strain.

The results are presented in Table 1 . The antimalarial activity was retained during fractionation, with a good activity observed for the aqueous fraction $(C)\left(\mathrm{IC}_{50}=2.7 \mu \mathrm{g} / \mathrm{mL}\right)$. The most active fraction was the ethyl acetate one (D) which displayed a remarkable $\mathrm{IC}_{50}$ value $(<1 \mu \mathrm{g} / \mathrm{mL})$. Cytotoxicity was evaluated on VERO and L6 cells. As previously observed for the decoction, the most active fraction (D) was not cytotoxic against VERO cells $\left(\mathrm{IC}_{50}>\right.$ $100 \mu \mathrm{g} / \mathrm{mL})$, and exhibited a low cytotoxicity against L6 cells $\left(\mathrm{IC}_{50}=57.4 \mu \mathrm{g} / \mathrm{mL}\right)$.

Table 1. In vitro antiplasmodial and cytotoxic activities of extracts obtained by successive liquid/liquid fractionation of $P$. acutangulum decoction. Results are in $\mu \mathrm{g} / \mathrm{ml}$ for extracts and positive controls.

\begin{tabular}{lccccc}
\hline & $\begin{array}{c}\mathrm{IC}_{50} \pm \mathrm{SD} \\
\text { P. falciparum } \\
\text { FcB1 }\end{array}$ & $\begin{array}{c}\mathrm{IC}_{50} \pm \mathrm{SD} \\
\text { P. falciparum } \\
\mathrm{NF54}\end{array}$ & $\begin{array}{c}\mathrm{IC}_{50} \pm \mathrm{SD} \\
\text { P. falciparum } \\
7 \mathrm{G} 8^{\mathrm{a}}\end{array}$ & $\begin{array}{c}\mathrm{IC}_{50} \\
\text { VERO } \\
\text { cells }\end{array}$ & $\begin{array}{c}\mathrm{IC}_{50} \pm \mathrm{SD} \\
\text { L6 cells }\end{array}$ \\
\hline (A) (decoction) & $3.3 \pm 0.4$ & $10.3 \pm 0.1$ & $19.0 \pm 2.7$ & n.t. & $>100$ \\
(B) (hexane) & $32.3 \pm 4.4$ & n.t $^{\mathrm{b}}$ & n.t & n.t. & $>100$ \\
(C) (water) & $2.7 \pm 0.7$ & $11.3 \pm 1.7$ & $13.6 \pm 0.3$ & n.t. & $>100$ \\
(D) (ethyl & $<1$ & $2.3 \pm 0.6$ & $2.6 \pm 0.02$ & $>100$ & $57.4 \pm 20.5$ \\
acetate) & $21.2 \pm 3.8$ & $9.4 \pm 0.2$ & $12.9 \pm 0.1$ & n.t. & $>100$ \\
(E) (water) & $0.18 \pm 0.03$ & $0.002 \pm 0.0001$ & $0.13 \pm 0.002$ & n.t. & n.t. \\
Chloroquine & n.t. & n.t & n.t & n.t. & $0.007 \pm 0.003$ \\
Podophyllotoxin & n.t. & n.t. & n.t. & $<0.02$ & n.t. \\
Doxorubicin & & &
\end{tabular}

${ }^{a} \mathrm{pLDH}$ (Plasmodium lactate dehydrogenase immunodetection) assay

${ }^{\mathrm{b}}$ Not tested

Pure compounds isolated from the AcOEt fraction were also evaluated for antiplasmodial activity against $P$. falciparum FcB1 and for cytotoxic activity on VERO cells (Table 2).

Table 2. Antiplasmodial activity ( $P$. falciparum chloroquine resistant FcB1 strain) and cytotoxicity of the pure compounds isolated from fraction D. Errors for individual 


\section{ACCEPTED MANUSCRIPT}

measurements differed by less than $20 \%$. Data represents the average of three independent determinations.

\begin{tabular}{lcc}
\hline & $\begin{array}{c}\text { Antiplasmodial activity } \\
\text { P. falciparum FcB1 } \\
\mathrm{IC}_{50}(\mu \mathrm{M})\end{array}$ & $\begin{array}{c}\text { Cytototoxic activity } \\
\text { VERO cells } \\
\mathrm{IC}_{50}(\mu \mathrm{M})\end{array}$ \\
\hline Catechin (1) & 72.3 & n.t. $^{2}$ \\
Wayanin (2) & 5.5 & $>200$ \\
Reynoutrin (3) & 26.5 & $>200$ \\
Guaijaverin (4) & 6.9 & $>200$ \\
Avicularin (5) & 64.5 & $>200$ \\
Quercitrin (6) & 71.4 & $>200$ \\
Chloroquine & 0.36 & $>200$ \\
\hline
\end{tabular}

${ }^{\mathrm{a}}$ Not tested

Our results thus provide the first evidence for antiplasmodial activity of the well-known

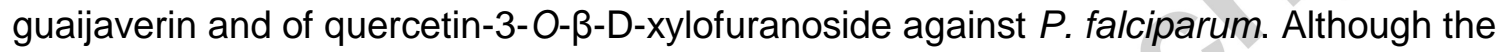
latter was recently isolated from Myrcia bella hydroalcoolic leaves extract (Saldanha et al., 2013), no common name was given to it. We therefore proposed to name it wayanin during public meetings realized in June 2015 in the Upper-Maroni villages, with the agreement of the Wayana traditional authorities, and in homage to the Wayana medicinal knowledge. The two compounds exhibited $\mathrm{IC}_{50}$ of 6.9 and $5.5 \mu \mathrm{M}$, respectively, and the other constituents of the fraction $D$ were only moderately active or inactive. To our knowledge, reynoutrin and avicularin had never been evaluated against $P$. falciparum. Quercitrin was already shown to exhibit moderate activity against $P$. falciparum (Ganesh et al., 2012; Liu et al., 2007; Murakami et al., 2001) although it was considered inactive in our study. If flavonoids are generally known for their moderate activity against various strains of $P$. falciparum (Ganesh et al., 2012; Torres-Mendoza et al., 2006), these molecules and their analogs are renowned for their ability to potentialize other molecules' activity such as artemisinin (Bilia et al., 2006; Bourdy et al., 2008; Ganesh et al., 2012; Rasoanaivo et al., 2011). They have also been considered as pharmacophore models in the search for molecules inhibiting fatty acids biosynthesis in the parasite (Gupta et al., 2010). In particular, several flavonoids including quercetin were found to exhibited strong activity $\left(\mathrm{IC}_{50} 0.5-8 \mu \mathrm{M}\right)$ towards three important 
enzymes (FabG, FabZ and Fabl) in a library's screening (Tasdemir et al., 2006) performed further to the discovery of luteolin-7-O-glucoside to be the first antimalarial natural product targeting the Fabl enzyme of $P$. falciparum (Kirmizibekmez et al., 2004).

Overall, none of the compounds isolated here turned out as active as fraction $D$ (the $5.5 \mu \mathrm{M}$ for wayanin corresponds to $2.4 \mu \mathrm{g} / \mathrm{ml}$ ). Hence, the excellent antiplasmodial activity of the fraction might not be due to one single component, but to a mixture of molecules, or to a synergistic action between them, as previously discussed by some authors for other traditional remedies (Deharo and Ginsburg, 2011; Houghton et al., 2007). A striking example is the pharmacodynamic synergy demonstrated in vitro between the Cinchona alkaloids found in Cinchona bark traditionally used for treatment of malaria (Rasoanaivo et al., 2011). Interestingly enough however, none of the isolated molecules was cytotoxic against VERO cells $\left(\mathrm{IC}_{50}>200 \mu \mathrm{M}\right)$.

It is worth mentioning that all isolated components except catechin are glycosylated quercetins. Because these compounds seem to be active as a whole, and because our previous work suggested an activity of the decoction per os (300 $\mu \mathrm{L} /$ day) on Plasmodium berghei NK65 infected Swiss male mice (Houël et al., 2015), it can be postulated that glycosylation plays a role in biological activity. As a matter of fact, it has been demonstrated that some quercetin monoglucosides are transferred more rapidly than the quercetin aglycone across the intestinal epithelium in rats (Gee et al., 2000). Further studies revealed that small intestine absorption in rats is determined by the type of sugar moiety, showing that within quercetin glycosylated derivatives, only Q3- and Q4'-glucosides were hydrolysed by $\beta$ glycosidases present in the small intestine, whereas other glycosides (Q3-galactoside, Q3rhamnoside or Q3-arabinoside) were resistant to intestinal hydrolysis (Arts et al., 2004). Similar results were found in human subjects (Graefe et al., 2001; Hollman et al., 1997), indicating that glycosylated quercetines may really account for the antimalarial potential of the $P$. acutangulum decoction altogether. 
Lastly, we investigated the in vitro anti-inflammatory activity of the ethyl acetate fraction (D) and the commercially available guaijaverin. For that, we tested their potential to inhibit the release of pro-inflammatory cytokines TNF- $\alpha$, IL-1 $1 \beta$, IL- 6 and IL-8, and the effect of these products on NO production. Indeed, the role of cytokines in malaria pathophysiology has been well documented. For example, it is now widely accepted that cytokines such as TNF and IL-1 are at the origin of systemic manifestations (anorexia, tiredness, aching joints, myalgia, headache, fever...) experienced by malaria patients (Burns et al., 2010; Clark et al., 2006; Lyke et al., 2004). Also, significantly elevated levels of IL-6 and IL-8 in patients' blood samples were associated with Plasmodium falciparum malaria severity among children and adults (Berg et al., 2014; Lyke et al., 2004). Diminished nitric oxide bioavailability may also contribute to the pathogenesis of severe malaria. For example, it was observed that children with severe malarial anemia showed evidence of pulmonary vasoconstriction, consistent with low NO bioavailability (Miller et al., 2013). The results of anti-inflammatory assays are presented in Figures 2 and 3. At $50 \mu \mathrm{g} / \mathrm{mL}$, the ethyl acetate fraction (D) significantly inhibited IL-1ß secretion (-46\%) and NO production (-21\%), as previously observed for the decoction (-58\% and $-13 \%$ respectively; Houël et al., 2015). The effect of (D) and guaijaverin (4) on the secretion of other cytokines was not significant. No effect on cell viability was observed during the assays for inhibition of cytokine secretion (data not shown). 


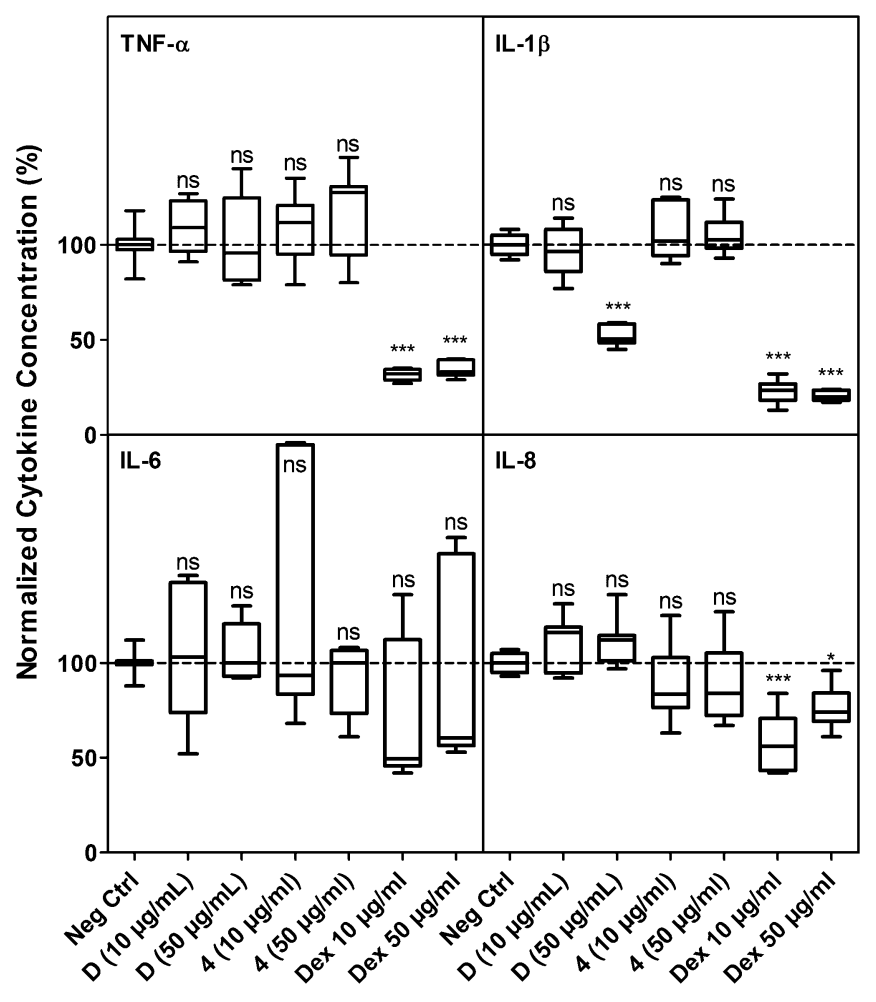

Fig. 2. Effect of $P$. acutangulum decoction ethyl acetate extract (D, $10 \& 50 \mu \mathrm{g} / \mathrm{mL})$, guaijaverin $(4,10 \& 50 \mu \mathrm{g} / \mathrm{mL})$ and dexamethasone (Dex, $10 \& 50 \mu \mathrm{g} / \mathrm{mL})$ on the secretion of TNF- $\alpha$, IL-1 $\beta$, IL-6, and IL-8. Concentrations have been normalized relatively to the corresponding negative control of each experiment (Neg Ctrl). Significance levels when compared to negative control as calculated by one-away ANOVA followed by Tukey's multiple comparison test are indicated above the boxes: ns not significant; ${ }^{*} p<0.05 ;{ }^{* *} p<$ $0.01 ;{ }^{* * *} p<0.001$. 


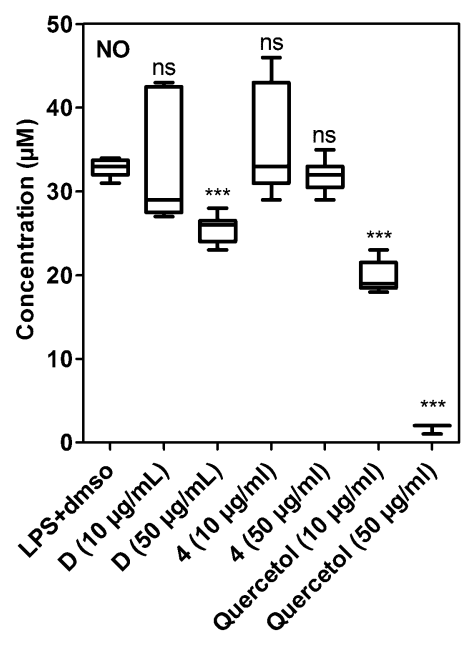

Fig. 3. Effect of $P$. acutangulum decoction ethyl acetate extract $(D, 10 \& 50 \mu \mathrm{g} / \mathrm{mL})$, guaijaverin $(4,10 \& 50 \mu \mathrm{g} / \mathrm{mL})$ and quercetol $(10 \& 50 \mu \mathrm{g} / \mathrm{mL})$ on NO secretion. Significance levels when compared to negative control (LPS+DMSO) as calculated by one-away ANOVA followed by Tukey's multiple comparison test are indicated above the boxes: ns not significant; ${ }^{*} p<0.05 ;{ }^{* *} p<0.01 ;{ }^{* *} p<0.001$.

These results obtained on pro-inflammatory cytokines are of particular interest compared to those obtained with the crude decoction. According to our previous results, the decoction

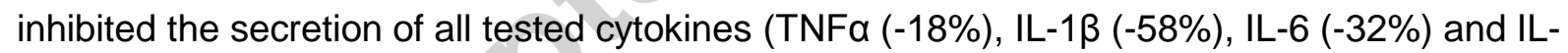
$8(-21 \%))$, suggesting a mild anti-inflammatory activity of the remedy. However, the results obtained on the ethyl acetate fraction (D) and on guaijaverin (4) showed a reduced (cytokines spectrum) to inexistent anti-inflammatory activity compared to the decoction, with a significant anti-inflammatory effect on IL-1 $\beta$ (-46\%) for fraction (D) at $50 \mu \mathrm{g} / \mathrm{ml}$ only. Clearly, the crude decoction was more anti-inflammatory than the purified extract or compound. It is reasonable to postulate that other anti-inflammatory compounds were present in the remedy and not isolated during the bioguided fractionation, based on antiplasmodial activity.

\section{Conclusion}




\section{ACCEPTED MANUSCRIPT}

Taking into account symptoms associated to the first intended pathology in crucial to understand the use and mode of action of traditional preparations. In many cases, interactions between compounds, i.e., pharmacodynamic synergies, complementary biological effects, contribute to its global biological activity (Bourdy et al., 2008; Rasoanaivo et al., 2011). This study adds new elements in this matter to our previous results on the decoction of $P$. acutangulum, a traditional antimalarial remedy of the Wayana Amerindians. Here, two antiplasmodial glycosylated flavonoids, guaijaverin and wayanin, were identified $\left(\mathrm{IC}_{50} 6.9 \mu \mathrm{M}\right.$ and $5.5 \mu \mathrm{M}$ respectively). However, none of the isolated compounds explained by itself the excellent activity of the ethyl acetate fraction, thus suggesting possible synergistic interactions between them. On the other hand, the ethyl acetate fraction (D) inhibited the secretion of IL-1 $\beta$ and NO production only, and guaijaverin (4) was inactive. Hence, the crude decoction was clearly more anti-inflammatory than (D) or compound (4). Therefore, it appears that the interactions between the decoction's constituents clearly contribute to the activity of the remedy. Considering that neither the isolated molecules nor the decoction were cytotoxic, these results speak in favor of the use of $P$. acutangulum as antimalarial phytotherapeutic remedy.

\section{Acknowledgments}

The authors are grateful to the Wayana population of Twenke-Taluhwen and Antecume-Pata for generously sharing their knowledge with us. We particularly Haiwé Aloiké from Twenke and Aïtalewa Palanaïwa from Antecume-Pata, who represented local authorities, for having attended the public meetings and for their trust and support concerning our research. We also thank André Cognat, from Antecume-Pata, for his support and welcome, and Amaipotï Twanké, Gran Man of Twenké, for having made this work possible.

Bernard Weniger (UMR 7200, France), and Nelly Frossard (UMR 7200, France) contributed to the study with their stimulating discussions. This article is particularly dedicated to the memory of 'Fanchon'- Marie-Françoise Prévost, who confirmed the botanical identification of 


\section{ACCEPTED MANUSCRIPT}

$P$. acutangulum and generously companioned us in our work on medicinal and aromatic plants of French Guiana.

This work has benefited from an Investissement d'Avenir grant of the ANR (CEBA: ANR-10LABX-0025).

\section{References}

Ahmed, S.A., Gogal, R.M., Walsh, J.E., 1994. A new rapid and simple non-radioactive assay to monitor and determine the proliferation of lymphocytes: an alternative to [3H]-thymidine incorporation assay. J. Immunol. Methods 170, 211-224.

Arts, I.C., Sesink, A.L.A., Faassen-Peters M., Hollman, P.C.H., 2004.The type of sugar moiety is a major determinant of the small intestinal uptake and subsequent biliary excretion of dietary quercetin glycosides. Br. J. Nutr. 91, 841-847.

Atchade, P.S., Doderer-Lang, C., Chabi, N., Perrotey, S., Abdelrahman, T., Akpovi, C.D., Anani, L., Bigot, A., Sanni, A., Candolfi, E., 2013. Is a Plasmodium lactate dehydrogenase (pLDH) enzyme-linked immunosorbent (ELISA)-based assay a valid tool for detecting risky malaria blood donations in Africa? Malar. J. 12, 279.

Benoit, F., Valentin, A., Pélissier, Y., Diafouka, F., Marion, C., Kone-Bamba, D., Koné, M., Mallié, M., Yapo, A., Bastide, J.-M., 1996. In vitro antimalarial activity of vegetal extracts used in West African traditional medicine. Am. J. Trop. Med. Hyg. 54, 67-71.

Berg, A., Patel, S., Gonca, M., David, C., Otterdal, K., Ueland, T., Dalen, I., Kvaloy, J.T., Molines, T.E., Aukrust, P., Langeland, N., 2014. Cytokine network in adults with Falciparum Malaria and HIV-1: increased IL-8 and IP-10 levels are associated with disease severity. PLoS ONE 9, e114480. 


\section{ACCEPTED MANUSCRIPT}

Bilia, A.R., Melillo de Malghaes, P., Bergonzi, M.C., Vincieri, F.F., 2006. Simultaneous analysis of artemisinin and flavonoids of several extracts of Artemisia annua L. obtained from a commercial sample and a selected cultivar. Phytomedecine 13, 487-493.

Bourdy, G., Willcox, M.L., Ginsburg, H., Rasoanaivo, P., Graz, B., Deharo, E., 2008. Ethnopharmacology and malaria: new hypothetical leads or old efficient antimalarials ? International Journal of Parasitology 38, 33-41.

Burns, J.J., Zhao, L., Taylor, E.W., Spelman, K., 2010. The influence of traditional herbal formulas on cytokine activity. Toxicology $278,140-159$.

Cachet, N., Hoakwie, F., Bertani, S., Bourdy, G., Deharo, E., Stien, D., Houël, E., Gornitzka, H., Fillaux, J., Chevalley, S., Valentin, A., Jullian, V., 2009. Antimalarial activity of Simalikalactone E, a new quassinoid from Quassia amara L. (Simaroubaceae). Antimicrob. Agents Chemother. 53, 4393-4398.

Clark, I.A., Budd, A.C., Alleva, L.M., Cowden, W.B., 2006. Human malarial disease: a consequence of inflammatory cytokine release. Malar. J. 5, 85.

Davis, A.L., Cai, Y., Davies, A.P., Lewis, J.R., 1996. ${ }^{1} \mathrm{H}$ and ${ }^{13} \mathrm{C}$ NMR assignments of some green tea polyphenols. Magn. Reson. Chem. 34, 887-890.

Deharo, E., Ginsburg, H., 2011. Analysis of additivity and synergism in the anti-plasmodial effect of purified compounds from plant extracts. Malar. J. 10, 55.

El Khadem, H., Mohammed, Y.S., 1958. Constituents of the leaves of Psidium guaijava, L. Part II. Quercetin, avicularin, and guaijaverin. J. Chem. Soc. (Resumed) 3320-3323.

Eparvier, V., Thoison, O., Bousserouel, H., Guéritte, F., Sévenet, T., Litaudon, M., 2007. Cytotoxic farnesyl glycosides from Pittosporum pancheri. Phytochemistry 68, 604-608.

Fleury, M., "Busi-nenge" ; les Hommes-forêt. Essai d'ethnobotanique chez les Aluku (Boni) en Guyane française, Université Paris 6 (Ed), 1991, Paris. 


\section{ACCEPTED MANUSCRIPT}

Fleury, M., 2003. Se soigner en forêt guyanaise: enquêtes sur l'automédication par les plantes médicinales chez les Amérindiens Wayana. In: Proceedings of the 5ème Colloque International d'Ethnopharmacologie, 8-10 Mai 2003. Valence, Espagne.

Fleury, M.,2007. Remèdes wayana-Wajana epit. Gadepam/CRDP (Ed.), Cayenne.

Gallo, M.B.C., Da Silva, F.C., Vieira, P.C., Fernandes, J.B., Da Silva, M.F.D.G.F., 2006. New natural products from Siphoneugena densiflora Berg (Myrtaceae) and their chemotaxonomic significance. J. Braz. Chem. Soc. 17, 279-288.

Ganesh, D., Fuehrer, H.P., Starzengüber, P., Swoboda, Khan, W.A., Reismann, J.A.B., Mueller, M.S.K., Chiba, P., Noedl, H., 2012. Antiplasmodial activity of flavonol quercetin and its analogues in Plasmodium falciparum: evidence from clinical isolates in Bangladesh and standardized parasite clones. Parasitol. Res. 110, 2289-2295.

Gee, J.M., DuPont, M.S., Day, A.J., Plumb, G.W., Williamson, G., Johnson, I.T., 2000. Intestinal transport of quercetin glycosides in rats involves both deglycosylation and interaction with the hexose transport pathway. J. Nutr. 130, 2765-2771.

Graefe, E.U., Wittig, J., Mueller, S., Riethling, A.K., Uehleke, B., Drewelow, B., Pforte, H., Jacobasch, G., Derendorf, H., Veit, M., 2001. Pharmacokinetics and bioavailability of quercetin glycosides in humans. J. Clin. Pharmacol. 41, 492-499.

Grenand, P., Moretti, C., Jacquemin, H., Prévost, M.F., 2004. Pharmacopées traditionnelles en Guyane. IRD (Ed.), Paris, p. 508.

Gupta, A.K., Saxena, S., Saxena, M., 2010. Integrated ligand and structure based studies of flavonoids as fatty acid biosynthesis inhibitors of Plasmodium falciparum. Bioorg. Med. Chem. Lett. 20, 4779-4781.

Houël, E., Fleury, M., Odonne, G., Nardella, F., Bourdy, G., Vonthron-Sénécheau, C., Villa, P., Obrecht, A., Eparvier, V., Deharo, E., Stien, D., 2015. Antiplasmodial and antiinflammatory effects of an antimalarial remedy from the Wayana Amerindians, French 


\section{ACCEPTED MANUSCRIPT}

Guiana: Takamalaimë (Psidium acutangulum Mart. ex DC.,Myrtaceae). J. Ethnopharmacol. 166, 279-285.

Ho, R., Violette, A., Cressend, D., Raharivelomanana, P., Carrupt, P.A., Hostettmann, K., 2012. Antioxidant potential and radical scavenging effects of flavonoids from the leaves of Psidium cattleianum grown in French Polynesia .Nat. Prod. Res. 26, 274-277.

Hollman, P.C.H., van Trijp, J.M.P., Buysman, M.N.C.P., van der Gaag, M.S., Mengelers, M.J.B., de Vries, J.H.M., Katan, M.B., 1997. Relative bioavailability of the antioxidant flavonoid quercetin from various foods in man. FEBS Lett. 418, 152-156.

Houghton, P.J., Howes, M.-J., Lee, C.C., Steventon, G., 2007. Uses and abuses of in vitro tests in ethnopharmacology: visualizing an elephant. J. Ethnopharmacol. 110, 391-400.

Kirmizibekmez, H., Calis, I., Perozzo, R., Brun, R., Dönmez, A. A., Linden, A., Rüedi, P., Tasdemir, D., 2004. Inhibiting activities of the secondary metabolites of Phlomis brunneogaleata against parasitic protozoa and plasmodial enoyl-ACP reductase, a crucial enzyme in fatty acid biosynthesis. Planta Med. 70, 711-717.

Kumar-Roiné, S., Matsui, M., Reybier, K., Darius, H.T., Chinain, M., Pauillac, S., Laurent, D., 2009. Ability of certain plant extracts traditionally used to treat ciguatera fish poisoning to inhibit nitric oxide production in RAW 264.7 macrophages. J. Ethnopharmacol. 123, 369-377.

Le Bras, J., Deloron, P., 1983. In vitro study of drug sensitivity of Plasmodium falciparum: evaluation of a new semi-micro test. Am. J. Trop. Med. Hyg. 32, 447-451.

Liu, Y., Murakami, N., Ji, H., Abreu, P., Zhang, S., 2007. Antimalarial flavonol glycosides from Euphorbia hirta. Pharm. Biol. 45, 278-281.

Lu, Y., Yeap Foo, L., 1997. Identification and quantification of major polyphenols in apple pomace. Food Chem. 59, 187-197. 


\section{ACCEPTED MANUSCRIPT}

Lyke, K.E., Burges R., Cissoko, Y., Sangare, L., Dao, M., Diarra, I., Kone, A., Harley, R.,

Plowe, C.V., Doumbo, O.K., Sztein, M.B., 2004. Serum levels of the proinflammatory

cytokines Interleukin-1 Beta (IL-1 $\beta$ ), IL-6, IL-8, IL-10, Tumor Necrosis Factor Alpha, and IL12(p70) in Malian children with severe Plasmodium falciparum malaria and matched uncomplicated malaria or healthy controls. Infect. Immun. 72, 5630-5637.

Miles, D.H., De Medeiros, J.M.R., Chittawong, V., Hedin, P.A., Swithenbank, C. Lidert, Z., 1991. 3'-formyl-2',4',6'-trihydroxydihydrochalcone from Psidium acutangulum.

Phytochemistry 30, 1131-1132.

Miller, L.H., Ackerman, H.C., Su, X.-Z., Wellems, T.E., 2013. Malaria biology and disease pathogenesis: insights for new treatments. Nat. Med. 19, 156-167.

Moravcova, J., Capkova, J., Stanek, J., Raich, I., 1997. Methyl-5-deoxy- $\alpha$ - and $\beta$-Dxylofuranosides. J. Carbohydr. Chem. 16, 1061-1073.

Murakami, N., Huq, M.M., Tamura, S., Itagaki, S., Horii, T., Kobayashi, M., 2001. New antimalarial flavonol glycoside from Hydrangeae dulcis folium. Bioorg. Med. Chem. 11, 24452447.

Rasoanaivo, P., Wright, C.W., Wilcox, M.L., Gilbert, B., 2011. Whole plant extracts versus single compounds for the treatment of malaria: synergy and positive interactions. Malar. J. $10,54$.

Rivero-Maldonado, G., Pacheco, D., Martin, L.M., Sanchez-Urdaneta, A., Quiros, M., Ortega, J., Colmenares, C., Bracho, B., 2013. Flavonoids extracted from Psidium species (Myrtaceae) in Venezuela. Rev. Fac. Agron. 30, 217-241.

Saldanha, L.L., Vilegas, W., Dokkedal, A.L., 2013. Characterization of flavonoids and phenolic acids in Myrcia bella Cambess. Using FIA-ESI-IT-MS ${ }^{n}$ and HPLC-PAD-ESIIT-MS combined with NMR. Molecules 18, 8402-8416. 


\section{ACCEPTED MANUSCRIPT}

Saxena, S., Chaturvedi, P.K., 1992. A novel cardenolide, canarigenin-3-O- $\alpha$ -

rhamnopyranosyl-(1-5)-O- $\beta$-D-xylofuranoside, from rhizomes of Convallaria majalis. J. Nat.

Prod. 55, 39-42.

Shu, J.-C., Chou, G.-X., Wang, Z.-T., 2012. One new diphenylmethane glycoside from the leaves of Psidium guajava L..Nat. Prod. Res. 26, 1971-1975.

Singh, P., Anand, A., Kumar, V., 2014. Recent developments in biological activities of chalcones: a mini review. Eur. J. Med. Chem. 85, 758-777.

Simirgiotis, M.J., Adachi, S., To, S., Yang, H., Reynertson, K.A., Basile, M.J., Gil, R.R., Weinstein, I.B., Kennelly, E.J., 2008. Cytotoxic chalcones and antioxidants from the fruits of Syzygium samarangense (Wax Jambu). Food Chem. 107, 813-819.

Stark, T., Bareuther, S., Hofman, T., 2005. Sensory-guided decomposition of roasted cocoa nibs (Theobroma cacao) and structure determination of taste-active polyphenols. J. Agric. Food Chem. 53, 5407-5418.

Tasdemir, D., Lack, G., Brun, R., Rüedi, P., Scapozza, L., Perozzo, R., 2006. Inhibition of Plasmodium falciparum fatty acid biosynthesis: evaluation of FabG, FabZ, and Fabl as drug targets for flavonoids. J. Med. Chem. 49, 3345-3353.

Torres-Mendoza, D., Gonzalez, J., Ortega-Barria, E., Heller, M.V., Capson, T.L., McPhail, K., Gerwick, W.H., Cubilla-Rios, L., 2006. Weakly antimalarial flavonol arabinofuranosides from Calycolpus warszewiczianus. J. Nat. Prod. 69, 826-828.

Vvedenskaya, I.O., Rosen, R.T., Guido, J.E., Russell, D.J., Mills, K.A., Vorsa, N., 2004. Characterization of flavonols in Cranberry (Vaccinium macrocarpon) powder. J. Agric. Food Chem. 52, 188-195.

Xue, Z.J., Chen, P., Peng, S.Y. and Li, Y.C., 2006. Synthesis and determination of absolute configuration of tetracetate 4a-carba-D-xylofuranoside. Tetrahedron 62, 199-204. 